\title{
El-Shadday dan Korelasinya dengan Dewi Karema dalam Mitologi Penciptaan Manusia Di Suku Minahasa
}

\author{
Regen Wantalangi \\ Sekolah Tinggi Teologi Tawangmangu \\ Firman Panjaitan \\ Sekolah Tinggi Teologi Tawangmangu \\ panjaitan.firman@gmail.com
}

\begin{abstract}
Understanding of God is very important in religious life, especially when religion is confronted with culture. There needs to be contextualization efforts in understanding God comprehensively so that it can be accepted from a religious as well as cultural perspective. Through this, God is not only understood correctly Biblically, but at the same time is understood based on the context of the local community. This article aims to find the understanding of God in the Minahasa context by contextualizing the understanding of God in the Bible with the local context. This article uses a qualitative method with a literature study approach for research into the Minahasa cultural context coupled with a critical interpretation of biblical research, especially Genesis 1:26-28. The results of the study prove that God, known as El Shadday in the Bible understanding can be contextualized with the understanding of Dewi Karema, so that God in the form of El Shadday understood by Minahasa culture is not just a masculine God but also a feminine God. Thus the God of El Shadday in the Bible is not a foreign God in the life of the Minahasa tribe, but a God who is very close to human life, especially in the figure of Dewi Karema.
\end{abstract}

Keywords: el shadday; dewi karema; contextualization; minahasa

\begin{abstract}
Abstrak
Pemahaman tentang Allah menjadi hal yang sangat utama dalam kehidupan beragama, terutama ketika agama diperhadapkan pada budaya. Perlu ada upaya kontekstualisasi dalam memahami Allah secara komprehensif sehingga dapat diterima dalam perspektif agama sekaligus budaya. Melalui hal ini, Allah tidak hanya dipahami dengan benar secara Alkitabiah, tetapi sekaligus dipahami berdasarkan konteks masyarakat setempat. Artikel ini bertujuan untuk menemukan pemahaman Allah dalam konteks Minahasa dengan cara mengkontekstualisasikan pemahaman tentang Allah dalam Alkitab dengan konteks setempat. Artikel ini menggunakan metode kualitatif dengan pendekatan studi literatur bagi penelitian terhadap konteks budaya Minahasa ditambah dengan tafsir kritis terhadap penelitian Alkitab, khususnya Kejadian 1:26-28. Hasil penelitian menunjukkan bahwa Allah, yang dikenal dengan nama El Shadday dalam pemahaman Alkitab dapat dikontekstualisasikan dengan pemahaman Dewi Karema, sehingga Allah dalam wujud El Shadday yang dipahami oleh budaya Minahasa bukan sekadar Allah yang maskulin melainkan Allah dalam wujud feminine, sehingga kehidupan El Shadday sangat dekat dengan kehidupan manusia.
\end{abstract}

Kata Kunci: el shadday; dewi karema; kontekstualisasi; minahasa 


\section{Pendahuluan}

Dalam kehidupan beragama di Indonesia, terdapat sebuah masalah yang senantiasa menjadi pergumulan bersama, yaitu ketika agama berhadapan dengan budaya. Padahal masalah berteologi dalam konteks budaya di Indonesia merupakan suatu keniscayaan, jika dilakukan upaya kontekstualisasi Alkitabiah (Panjaitan \& Siburian, 2019). Karena melalui upaya kontekstualisasi Alkitabiah, Injil tidak menjadi asing dan dapat diterima oleh budaya atau adat istiadat yang ada di masyarakat. Bahkan Injil dapat menjadi penerang dan pemurni bagi budaya yang ada, sehingga orang yang hidup dalam budaya tidak disingkirkan melainkan hidup di dalam kesatuan antara Injil dan budaya (Setiawan, 2020).

Dalam kehidupan, adat sama seperti hikmat, karena merupakan hasil dari pertimbangan yang dilahirkan dari pengalaman dan pengamatan yang dipengaruhi oleh situasi sekitar dan kepercayaan (agama) (Natar, 2012). Adat-istiadat ini merupakan hasil pemikiran suatu masyarakat yang sangat berharga, sehingga lewat adat-istiadat terbentuklah suatu disiplin dan peraturan dalam kelompok masyarakat. Dari adatistiadat inilah lahir cerita-cerita rakyat dan cerita-cerita suci tentang ketuhanan yang disebut sebagai mitologi. Mitos adalah buah budaya manusia sekaligus dijadikan sebagai 'teks suci' dalam masyarakat yang selalu hadir dalam setiap detak jantung peradaban manusia (Lubis, 2011). Cerita-cerita suci kadang bervariasi, ini terjadi karena ceritacerita yang dilahirkan lewat adat-istiadat berupa cerita lisan yang sudah sangat lama diceritkan secara turun-temurun dari zaman ke zaman dari generasi ke generasi. Semua orang tua ingin melihat anak-anak mereka bertumbuh dan menjadi orang yang memiliki etika yang baik sesuai norma dalam adat istiadat. Ibu adalah orang pertama yang dalam hidup hampir setiap manusia memberikan pengajaran (bdk. Ams. 4:6) (Natar, 2012). Pengaruh seorang ibu sangat besar dalam kehidupan dan perkembangan anak. Dalam prosesnya, seorang anak akan lepas dari pemantauan seorang ibu jika telah memasuki proses pengenalan terhadap keadaan yang ada di sekitar. Proses pengenalan ini sangat dipengaruhi oleh kebiasaan orang-orang terdekat dan adat-istiadat di mana seorang anak itu dibesarkan (Etikawati et al., 2019).

Sebagai suku yang besar, suku Minahasa memiliki banyak adat-istiadat yang mereka warisi dari nenek moyang yang sampai hari ini masih mereka jaga dan jalankan dalam kehidupan sehari-hari, termasuk mitologi kisah penciptaan manusia. Dalam salah satu pemahaman mitologinya, suku Minahasa memercayai bahwa mereka terbentuk dari gabungan sembilan suku yang secara geografis berada di Utara pulau Sulawesi, yaitu suku Toutemboan, suku Toubulu, suku Tousea, suku Taulour, suku Tousawang, suku Toupasang, suku Toupenosakan, suku Toubantik, dan suku Tousiau. Nama 'Minahasa' berarti 'persatuan', yaitu persatuan dari kesembilan suku itu. Mereka memahami bahwa pada dasarnya mereka berasal dari satu rumpun, satu keturunan dari leluhur mereka yang mereka sebut dengan Opo Lumimuut (orang tua perempuan pertama di bumi), yaitu manusia pertama yang diciptakan oleh Dewi Karema (Wenas, 2007). Tujuan dari mitologi penciptaan manusia di suku Minahasa ialah sebaagai pengingat untuk semua keturunan suku Minahasa bahwa seorang Dewi Karema telah datang di dunia dan menciptaakan 
Lumimuut sebagai manusia pertama di dunia sebagai representasi Tuhan yang mahapencipta, karena dari perempuanlah kehidupan itu berasal.

Sudah ada kajian mengenai El-Shadday dan mitologi penciptaan manusia, seperti penelitian Szuster tentang masalah teologi dalam mengenal Allah dengan kata ganti, kata benda, dan kualitas laki-laki pada zaman ini, juga pentingnya pengeksplorasian penyebutan Allah dalam tradisi Yahudi. Ditulis dalam bahasa Spanyol yang berjudul "Teología feminista judía: diversas maneras de nombrar a la divinidad en la liturgia judía" (Szuster, 2014) juga penelitian Tiwery tentang manusia pertama yang dikaitkan dengan mitologi penciptaan perempuan di tanah Maluku (Tiwery, n.d.). Namun demikian untuk penelitian tentang El-Shadday dan korelasinya dengan Dewi Karema dalam mitologi penciptaan manusia di suku Minahasa belum banyak diteliti, terlebih khusus yang berkaitan dengan usaha untuk menemukan point of contac tentang El-Shadday dan korelasinya dengan Dewi Karema dalam hal pengkontekstualisasian kebenaran di dalam budaya (Setiawan, 2020). Berdasarkan masalah di atas, maka penelitian ini hendak membuktikan bahwa pemahaman suku Minahasa mengenai sosok Dewi Karema sebenarnya merujuk pada sosok Allah yang dikenal dengan nama El Shadday seperti yang dituliskan dalam Perjanjian Lama (Panjaitan, 2020).

\section{Metode}

Metode yang digunakan adalah metode kualitatif dengan pendekatan studi literatur. Langkah dalam pendekatan ini dilakukan dengan mengumpulkan data pustaka, membaca dan mencatat, dan pengelolaan data penelitian (Kartikaningrum, 2015). Dalam penelitian ini, khususnya saat membahas tentang pemahaman tentang Allah dalam Perjanjian Lama, akan digunakan pendekatan hermeneutik historis-kritis, yaitu sebuah upaya untuk memahami teks berdasarkan konteks, situasi social dan terutama sitz im leben (setting inflife) yang menjadi latar belakang terbentuknya teks tersebut (Panjaitan, 2021). Sumber utama adalah PL, secara khusus tulisan-tulisan yang berkaitan dengan pembahasan dan melibatkan model teologi kontekstual, adapun model kontekstual yang dipakai adalah model sintesis kontekstual. Sedangkan untuk membahas tentang pemahaman mengenai Dewi Karena dalam religi suku Minahasa, yang dilihat dalam perspektif Alkitabiah, akan digunakan model sintesis kontekstual berupaya mengembangkan segala sesuatu secara dialetis dan kreatif (Setiawan, 2021, p. 4). Penggunaan model sintesis kontekstual ini akan mengerucut pada pemaparan mengenai korelasi antara El-Shadday dan Dewi Karema.

\section{Hasil dan Pembahasan}

\section{Pemahaman tentang Allah atau El dalam Perjanjian Lama}

Jauh sebelum terbentuknya patriarkh, di Mesopotamia telah dikenal sistem keallahan politeisme, di mana El dikenal sebagai kepala dari para dewa (pemimpin panteon), dan hal ini didukung dalam penemuan naska-naska Ugarit (Hinson, 2012). Para penulis kitab Torah juga memberikan indikasi mengenai Allah yang disembah oleh para patriarkh. Lumingkewas mengatakan bahwa ada dua perbedaan penyebutan Allah yang 
disembah oleh para patriarkh, yaitu: pertama, Allah leluhur yang dihubungkan dengan para pendahulu Israel yang sering tidak memberikan identitas diri, seperti dalam Kejadian 31:5, 29, 42; 46:3; 50:17; Keluaran 15:2; 18:4 (di mana penggunaan istilah elohei sering merujuk pada Allah patriarkh namun tidak memberikan penekanan tentang nama Allah patriarch). Kedua, penyebutan Allah telah menggunakan formula lengkap dalam penyebutan Allah seperti "Allah Abraham dan Allah Yakub" formula ini mengindikasikan bahwa Allah tersebut disembah oleh kelompok atau individu, di mana dalam penyebutan telah melekatkan/menambahkan nama mereka dibagian akhir nama Allah mereka, seperti "elohe Abraham" (Lumingkewas, 2017). Namun semua variasi yang ada di kitab Kejadian merupakan perkembangan dari figur El itu sendiri. El yang disembah oleh para patriarkh, hal ini dapat didukung dengan bukti sejarah yang membahas tentang sistem keallahan di Timur Tengah Kuno (Mesopotania dan Kanaan) yang didukung dengan naskah-naskah Ugarit.

Penggunaan nama El dalam penamaan seorang anak juga mendukung bahwa El adalah yang dikenal dalam kisah Kejadian seperti Abraham yang memberi nama kepada anaknya Isma-El (El telah memperhatikan Kej. 16:11), Yakub mendapatkan nama baru yaitu Yisra-El (Kej. 32:28), Israel membangun Mezbah dengan nama El Elohe Yisrael (Kej. 33:20), dan memberi nama ketika mendirikan tugu di Beth-El (Kej. 35:15). Para bapa leluhur Israel penggunakan nama El atau Elohim (dalam bentuk jamak) sebagai suatu bentuk penghormatan ketika mereka berbicara tentang Allah (Hinson, 2012).

\section{Pemahaman tentang El-Shadday dalam Perjanjian Lama}

Leluhur Israel mengenal Allah dengan sebutaan El-Shadday yang dikemudian hari dalam peristiwa Sinai Allah memberi klarifikasi kepada Musa "Aku telah menampakan diri kepada Abraham, Ishak dan Yakub sebagai Allah Yang Mahakuasa (El-Shadday), tetapi dengan nama-Ku TUHAN (Yahweh) Aku belum menyatakan diri" (Kel. 6:2). Pencetusan nama El-Shadday ini berasal dari sumber P (sumber kepenulisan Priest). El-Shadday selain dikenal secara umum sebagai Allah yang mahakuasa, sebagaimana Lumingkewas mengutip David Biale, mengatakan bahwa Shadday juga berarti buah dada, dan sang ilahi ini dapat dimengeti sebagai Allah yang memiliki sifat feminin (bahkan bergender feminin) dan dapat juga disangkutkan dengan Dewi Athena yang memiliki banyak payudara (Lumingkewas, 2017). Maller juga mengatakan bahwa, "El Shadday is a feminine image because a mother gives unearned love naturally. The Torah of kindness is on her tongue (Prov. 31:26). Adonai is a masculine image because the Book of the Covenant is filled with Mitsvot (Ex. 20:1-24:12). We have long tilted toward the strict rule of law. We should be more in the middle as scripture says, "Lodge between my breasts." (Song of Songs 1:13) (Maller, n.d.).

Clanton juga memaparkan bahwa El-Sadday, yang pada umumnya dipahami sebagai "Allah Yang Mahakuasa" dapat juga ditafsir sebagai "Allah atas payudara" atau "Allah yang berpayudara" (Clanton, 1990, p. 22). Narasi tentang Yakub yang memberkati putera-puteranya dalam Kejadian 49:25 mendukung hal ini di mana dikatakan bahwa Allah El-Shadday akan memberkti mereka dengan berkat berkat buah dada (Shad) dan 
kandungan (Racham). Sangat jelas bahwa ayat ini menggambarkan Allah sebagai ibu yang mencurahkan berkat payudara dan rahimnya untuk anak-anak Yakub (Trible, 1992).

Dalam penggunaan selanjutnya nama EL-Shadday dileburkan dengan nama Yahweh, ini terjadi karena sumber kepenulisan yang berbeda yaitu sumber Y (Yahwist). Sumber Y merupakan sumber yang mengangkat nama Yahweh, dan tulisan-tulisan dari sumber Y ini berasal dari zaman pemerintahan raja Daud, ditulis pada abad ke- 9 di istana Daud (Takaendengan, 2018). Sumber Y menganggap bahwa Yahweh adalah Allah yang universal, Allah seluruh umat manusia. Pada zaman Enos manusia mulai memanggil nama Yahweh (Kej. 4:26). Bahkan sumber Y lebih bercorak patriarkhis karena perkiraan kepenulisannya pada zaman pemerintahan Daud. Namun, perlu dipahami bahwa pandangan sumber $\mathrm{Y}$ adalah pandangan teologis dan bukan bukti kesejarahan atau ingatan historis (Vriezen, 2000). Walaupun dipandang sebagai patriarkhis dalam buku the book of J yang ditulis oleh David Rosenberg and Harold Bloom, mereka berusaha memperkenalkan bahwa sumber Y adalah hasil tulisan dari kelompok atau individu yang memiliki sudut pandang feminisme sehingga memperkenalkan Yahweh sebagai Allah yang memiliki sifat feminis. Bahkan dengan tegas dikatakan bahwa sumber Y ditulis oleh kelompok perempuan, sehingga selalu berpandangan feminis (Rosenberg \& Bloom, 1990).

Sehingga dari sumber kepenulisan manapun dalam Torah, beranggapan bahwa ElShadday yang di kemudian hari memperkenalkan diri sebagai Yahweh Sang Pencipta manusia, dikenal sebagai Allah feminis karena memberi kehidupan kepada manusia seperti yang terdapat dalam Kejadian 2:7, Allah-lah yang membentuk manusia dari debu dan memberikan nafas hidup kepada mereka sehingga mereka hidup. Dalam Ayub 33:4 dikatakan bahwa Allah sendiri yang telah menjadikan Ayub dan memberikan nafas sehingga Ayub dapat hidup. Allah juga sering digambarkan sebagai induk burung, "... oleh TUHAN, Allah Israel, yang di bawah sayap-Nya engkau datang berlindung” (Ruth 2:12); “... sembunyikanlah aku dalam naungan sayap-Mu” (Mzm. 17:8); "Dalam naungan sayap-Mu aku akan berlindung ..." (Mzm. 57:1). Berbicara mengenai induk ayam atau pun burung yang akan selalu menaungi anak-anaknya adalah induk betina, dengan kata lain ayat-ayat ini sedang menunjukan sifat Allah yang feminis.

\section{Mitologi Penciptaan Manusia Di Suku Minahasa}

Dalam masyarakat Minahasa banyak sekali versi tentang mitologi kisah penciptaan manusia, namun semua itu selalu berawal dari kisah seorang Dewi yang turun ke dunia dan menciptakan manusia, beberapa cerita yang sangat kuat dan paling dipercaya di masyarakat Minahasa sampai saat ini yaitu:

\section{Kisah Penciptaan Manusia Menurut Suku Bantik Minahasa}

Pada mulanya, Ponaedan (keset kaki para dewa) tenggelam akibat kekacauan yang terjadi, sehingga Ponaedan hancur dan tenggelam. Namun, ada sedikit tandusan yang tersisa di ujung Ponaedan dan diatas tandus itu terdapat sebuah batu besar, diatas batu itu turunlah Empung (Tuhan) yang bernama Dewi Kadema (dapat juga dibaca Karema) 
dia datang dari kalrutuang (sorga), dan berdiri di atas batu itu, ditangannya ada Tingkayuan (cambuk), sejauh mata memandang ia hanya melihat lautan belaka. Kemudian Dewi Kadema mengangkat Tingkayuan yang sakti itu dan berkata "Adodou adodou tanah Ponaedan timagongte ada bobodone dumulru kumilra kalrotou te nai age nu pung-pung bo kayu" (Oh tanah Ponaedan telah tenggelam, biarlah terjadi guntur dan kilat dan timbullah tanah yang baru yang ditumbuhi dengan rerumputan kemudian dengan pohon-pohon kayu yang kecil-kecil sampai yang besar-besar, juga segala jenis rumput dan kayu), maka dengan sekejap terjadilah seperti yang Dewi Kadema inginkan. Dari dalam batu itu muncullah seorang anak laki-laki, lalu langsud sujud menyembah kepada Dewi Kadema. Kemudian Dewi Kadema berkata, "skarang kita kase nama pa ngana Toada, karna kita da dapa pangana di Moada” (sekarang kuberi engkau nama Toada/'Toar' karena kamu timbul dari Moada). Dewi Kadema dan Toada pun membuat patung dari lumut dan kemudian patung itu dibawa oleh Dewi Kadema di kalrutuang, dari sana Dewi Kadema turun kembali kebumi sudah bersama-sama dengan perempuan yang sangat cantik dan itu adalah patung yang terbuat dari lumut sehingga patung itu diberinama Lumimuut. Toada dan Lumimuut pun menikah dan beranak-cucu. ${ }^{1}$

\section{Kisah Penciptaan Manusia Menurut Suku Toubulu Minahasa}

Kisah penciptaan yang kedua ini dimuat dalam nyanyian upacara adat suku Minahasa, yang berjumlah 28 syair yang berjudul De Zang Van Karema (nyanyian Dewi Karema), namun yang akan dimuat hanya yang berkisahkan tentang penciptaaan (Kol, 1903).

Syair petama: Oh talian nio untenge minatontonai, eh rambi-rambian. Siminatontonai wanam puruk u langi, eh rambi-rambian Si zei'kan meilengkaz, wo mawiame dungus intanak, eh rambi-rambian (Wahai dengarkanlah cerita yang telah diturunkan, eh bunyikanlah gong. Cerita yang telah diturunkan dari atas langit, eh bunyikanlah gong. Dia (Dewi Karema) tidak dilahirkan ketika datang dan ada di muka bumi, eh bunyikanlah gong).

Syair kedua: Niakumo si mahawe'ena'ase, yah wiamo angka'aya'an. Yah werenanku an tanak, leme'loyo kampe. Wo Aku sumaru, sendangan timu. Yah, sinumpak um berenku, un Akel Matutung. Yah, Tumarak-tak, an tali watu ma ragos. Wo ni'ilek-ku tawi ni'itu, sumo'so'ane me-ngasin. (Akulah 'Dewi Karema' pemberi ingatan kesadaran berpikir dan aku telah ada di dunia ini. Aku melihat tanah permukaan bumi masih lembut berlumpur. Lalu aku menghadap arah tenggara. Mataku dihadang oleh pemandangan sebatang pohon Aren pohon saguer. Dan terdengar bunyi gemeretak, buah pohon Aren jatuh ketanah. Dan kulihat dekat pohon itu, ada sungai yang airnya mengalir kelaut).

Syair keempat: Wo mawiling Aku, sumaru sendangan Amian. Yah , kina patesanku, un Asa retik. Yah ma'tou karete ni'itu , un Tu'is Rarawir. Wo rimuru' ma'wire-wirei , u la'it um bene'. (Dan aku mengada ke arah timur laut. Dan aku memperhatikan pohon "Asa",

\footnotetext{
${ }^{1}$ Cerita ini diambil dari kisah cerita rakyat Minahasa yang diceritakan oleh Joutje A. Koapaha, pada 2006, dan dimuat dalam Sejarah Toar dan Lumimuut (nenek moyang Minahasa) - Hardi_Saerang (wordpress.com) pada 18-05-2021. 10:47
} 
jelaga. Dan pohon yang bertumbuh di dekatnya adalah pohon T u 'I (sejenis pohon dengan batang yang lembut). Dan pohon yang di samping yang sedang melambai adalah pohon daong nasi).

Syair kelima: Tumondong Aku mapa-saru, Amian talikuzan. Yah, kina werenanku witu , um-Bangelei ne Kotulus. Yah Karuru' karete ni'itu, um Bawali Kundamah. Yah minalung ni'itu , un Tewasen ne Rumopa. (Lalu aku mengadah arah Barat laut. Dan aku melihat tanaman obat wangelei (sejenis temulawak). Dan disudut dekat situ, ada tanaman wawali kundamah (pohon kencur). Dan pohon yang menaungi tempat itu adalah pohon tewasen (pohon katu yang batangnya menghasilkan sagu).

Jika diklasifikasikan, maka syair pertama sampai kelima adalah proses penciptaan manusia pertama yang dinamakan Lumimuut perempuan yang cantik.

Syair keenam: Kamuria aku mapasaru, timu'talikuzan. Yah, kapatesanku ma-witu, un ayamen ka'ukur. Yah sanaremong witu, un-tambelang tumitikak tabelang. Ta'an un atang witu nate si rarahe, menorome niaku. (Kemudian aku menghadap arah barat daya. Dan pandanganku tertumbuk pada pohon ayamen (silar/daun tikar). Dan satu rumpun dengan itu, adalah pohon bamboo, tabelang (tunas bambu yang dapat diartikan sebagai kelahiran). Tetapi dari arah itu, hati dan kemauan si gadis 'yang baru muncul/ lahir sudah teguh dan dia berjalan lurus kearahku).

Syair kedelapan: Witu kai ma'esa'an sana zizikezan, tu le'os wo u lewo. Yah sanawali mo kai, I minange witu Mapawe'a-we'an. In toro-itu , kai Timou mina'elu-eluzan mahwatu. Yah , witu kai lawiz , wo zei'kazei'an. (Mulai waktu itu kita bersatu saling terikat dalam suka mapun dalam duka. Dan bersama-sama kita pergi ke-tempat tinggal kita. Waktu itu kita berdua hidup berkasih-kasihan dan menyatu. Dan disitulah kita hidup diberkati dan senantiasa berkecukupan)

Mengenai kisah penciptaan ini beberapa pertimbangan muncul di mana tokoh feminis sangat ditonjolkan baik sang Tuhan yaitu Dewi Karema dan manusia pertama yang diciptakannya yaitu Lumimuut, memang sering juga berganti-ganti antara Toar dan Lumimuut siapa yang pertama. Namun analisis dari J.A.T. Schwartz, seorang zending di Minahasa, mengatakan bahwa kisah ini hendak mengangkat suatu kisah tentang Si Apok Ni Mema'Untana' (leluhur Lumimuut) yang membuat tanah agar dapat didiami dan ditempati oleh keturunan-keturunannya (Schwatrz, 1907). Schwartz memulai argumennya dengan mengangkat kisah tentang seorang perempuan yaitu Lumimuut. Seorang sejarawan Minahasa Jessy Wenas memaparkan bahwa dua syair yang biasa digunakan dalam upacara Mangorai berkisahkan tentang seorang perempuan yang bernama Lumimuut dan kemudian dilanjutkan dengan kisah pertemuan antara Lumimuut dan Toar (yang nantinya menjadi suami istri, menjadi nenek moyang pertama orang minahasa) (Taulu, 1977).

Di sini nampak bahwa perempuan memiliki kedudukan tinggi dalam kisah mitologi suku Minahsa, perempuan sebagai pencipta, perempuan sebagai ciptaan pertama, dan perempuan sebagai cikal-bakal kehidupan manusia. Juga perempuan adalah pembentuk sebuah kumpulan masyarakat yang tersebar menjadi sub-sub suku di tanah Minahasa. Perempuan yang melahirkan, membesarkan, merawat dan menjaga kehidupan 
itu (Tiwery, n.d.). Karena di dalam kandungan seorang ibu Minahasa, memiliki makna yang luas yaitu sebagai tempat pertemuan dari kejadian yang sudah berlalu, sebagai tempat pertemuan apa yang sedang terjadi, dan sebagai tempat pertemuan apa yang akan terjadi di masa depan (Kapahang-Kaunang, 1993).

\section{El-Shadday dan Korelasinya dengan Kisah Dewi Karema}

\section{El-Shadday dalam Kisah Penciptaan Kejadian Pasal 1}

Kisah tentang pengutusan Musa (Kel 6:1-13) memiliki sumber kepenulisan yang sama dengan kisah penciptaan dalam Kejadian pasal 1. Sumber P adalah pengarang dari dua kisah ini. Dalam kisah Kejadian sumber P memakai kata Elohim sedangkan dalam kisah pengutusan Musa sumber P memakai kata EL-Shadday untuk penggunaan nama Allah. Ini tidaklah jauh berbeda Allah yang dimaksut dari dua kisah ini adalah Allah yang sama bahkan sangat jelas sumber P menonjolkan tentang kesetaraan gender dari dua kisah ini.

Kejadian satu mengisahkan tentang penciptaan dunia dan segala makhluk di dalamnya termasuk manusia. 'Adam artinya manusia, namun oleh hermeneutik Kristen dan ajaran gereja sering kata 'adam tertuju kepada satu manusia yang berjenis kelamin maskulin, sehingga tidak heran sampai pada zaman ini ketika mendengar kata 'adam konotasinya pasti langsung tertuju kepada laki-laki yang diciptakan Allah di taman Eden. Atau pun salam sapaan yang sering terdengar "kaum Adam" yang artinya kaum lelaki (tertuju kepada kaum maskulin).

Hal ini sangatlah jauh berbeda dengan maksud dari ayat 26 Kejadian pasal 1 itu tentang 'adam yang artinya Manusia. Kata 'adam memiliki morfologi: kata benda, maskulin, singuler, artinya 'Manusia'. Hal yang menarik untuk diperhatikan adalah bentuk tunggal dari kata ini, yang kemudian dapat diartikan bahwa manusia yang dimaksud disini adalah manusia yang satu, manusia dalam bentuk kesatuan, manusia dalam bentuk kesempurnaan yaitu manusia yang esa. Bukan berarti manusia itu hanya laki-laki saja yang dimaksud dalam ayat ini, karena di ayat selanjutnya menjelaskan siapa manusia yang satu itu.

Ayat 26 menegaskan bahwa yang diciptakan Allah, melalui dialog dengan diri-Nya sendiri, adalah manusia ('adam); namun perlu dipahami bahwa yang dimaksud dengan manusia di sini bukanlah manusia dalam arti sendirian, melainkan dalam pengertian kolektif, sehingga bentuk kolektif ini lebih baik dimengerti dalam arti: kesatuan umat manusia atau kemanusiaan secara umum (Lempp, 1987). Kata adam berbentuk kata benda, maskulin dan selalu berbentuk tunggal. Kata adam tidak pernah digunakan dalam bentuk jamak, tetapi dalam penggunaannya selalu berbentuk jamak, sehingga terjemahan yang tepat dari kata adam adalah umat manusia (Luther menggunakan kata menschen (human being) untuk menerjemahkan kata Adam) (Rad, 1979). Dalam lanjutan ayat 26, penggunaan bentuk jamak dari kata adam (umat manusia) semakin ditegaskan melalui kata wayirdu [(dan) agar mereka memerintah] (van Wolde, 1997). Kata wayirdu, berasal dari kata radah (memerintah) yang dilengkapi dengan kata ganti orang ketiga, jamak (mereka), ini berarti Tuhan menugaskan umat manusia (manusia dalam bentuk jamak) 
untuk memerintah. Dari sini dapat diambil kesimpulan bahwa keberadaan kata adam sebenarnya mewakili keberadaan seluruh umat manusia, meskipun mengambil bentuk tunggal (Stanislaus, 2019).

Allah membuat ('asah) manusia menurut gambar (tselem) dan rupa (demuth) Allah. Kata tselem berarti 'patung yang dipahat untuk melukiskan seseorang', dan dapat juga dipahami sebagai 'jiplakan yang secara konkret memiliki keserupaan fisik antara patung dengan yang dipatungkan', dan semua terjemahan ini menunjuk pada pengertian duplikat (Singgih, 2011). Dengan demikian diciptakannya manusia menurut gambar Allah tidak boleh dimengerti hanya mengenai kerohanian saja, melainkan harus dimengerti juga mengenai kejasmanian manusia. Manusia selengkapnya, lahiriah dan batiniah, diciptakan seturut, seakhlak, setabiat dan sewatak dengan Allah (Lempp, 1987). Sedangkan kata demuth memiliki arti yang lebih umum, yang berarti 'keserupaan dalam rupa, perwujudan, atau apa yang tampak', ini berarti bahwa keberadaan manusia memiliki keserupaan dengan Allah (van Wolde, 1997). Kedua kata ini (tselem dan demuth) bukanlah merupakan dua konsep yang terpisah dan berdiri sendiri-sendiri, bahkan kata demuth menjadikan arti dari tselem lebih dalam lagi, yaitu menjadikan manusia sebagai makhluk yang memiliki kesegambaran dan keserupaan yang langsung dengan Allah; dan hal ini menunjukkan makna bahwa kehadiran manusia di dunia merupakan representasi dari kehadiran Allah secara langsung (Stanislaus, 2019).

Manusia yang diciptakan menurut 'gambar dan rupa Allah' tidak mengartikan bahwa manusia sama dengan Allah, melainkan merupakan perwujudan yang tampak dari Allah yang tidak tampak. Jadi muatan kata ini merupakan cerminan, penghadiran, perwujudnyataan dan perwakilah Allah dan kuasanya. Manusia bukan sakadar memiliki relasi yang sangat erat dengan Allah, tetapi sekaligus menghadirkan dan mewakili Allah di dunia, sehingga manusia memeroleh kuasa untuk melestarikan dan mengharmonisasikan seluruh ciptaan atas nama Allah (Singgih, 2011). Namun frasa manusia adalah gambar dan rupa Allah bukan berarti manusia adalah makhluk yang immortal (kekal), melainkan memiliki keistimewaan dibandingkan dengan makhlukmakhluk lain dan keistimewaan yang utama adalah tanggung jawab (Stanislaus, 2019). Manusia, sebagai gambar dan rupa Allah, bertanggung jawab kepada Allah untuk memelihara seluruh ciptaan dan kehidupan yang ada. Untuk itu, frasa 'gambar dan rupa Allah' sebenarnya mengacu pada tugas dan tanggung jawab manusia sebagai rekan kerja Allah.

Tugas dan tanggung jawab sebagai 'gambar dan rupa Allah', dipertegas melalui perintah Allah kepada manusia untuk 'memerintah terhadap ikan yang ada di laut dan burung di udara dan segala binatang (ternak dan buas) yang ada di bumi dan semua binatang yang melata yang merayap di bumi'. Kata memerintah diterjemahkan dari kata radah, yang secara etimologis berarti 'menginjak-injak (buah anggur), dan hal ini dipakai dalam konteks pengirikan anggur. Namun untuk konteks penciptaan, arti etimologi dari radah tidak bisa dipakai, karena arti radah di sini senantiasa dikaitkan dengan perkataan Allah yang mengatakan bahwa tujuan dari penciptaan manusia sebagai gambar dan rupa Allah adalah untuk memerintah 'sama seperti Allah' memerintah segala ciptaannya. Jadi 
bukan untuk menginjak-injak dan mendominasi ciptaan yang lain, melainkan untuk memerintah alam sama seperti Allah memerintah seluruh ciptaan-Nya. Inilah konsekuensi dari kesegambaran dan keserupaan manusia dengan Allah, yaitu ditetapkan dan didudukkan sebagai 'wakil Allah' dalam dunia. Jadi walaupun di satu sisi manusia merupakan sebagian dari penciptaan, namun di sisi lain manusia ditugaskan memelihara ciptaan lain dengan jalan memerintah mereka. Namun perlu dicatat bahwa cara manusia memerintah harus didasarkan pada cara Allah memerintah, karena sebagai 'wakil Allah' manusia tetap tunduk kepada Allah dan kemuliaan manusia tidak terletak pada penguasaannya terhadap ciptaan yang lain, melainkan terletak pada ketaklukan dan tanggung jawabnya kepada Allah. Jadi di sini semakin jelas bahwa kesegambaran dan keserupaan manusia dengan Allah merupakan bentuk persekutuan dan keterpautan manusia dengan Allah, yang semuanya berawal dari anugerah dan karunia Allah di mana manusia harus merespons semua itu dengan kepercayaannya kepada Allah. Di luar pertalian manusia dengan Allah, tidak akan ada kesegambaran dan keserupaan pada manusia (Westermann, 1984).

Ayat 27 lebih memberi penjelasan tentang 'adam, "Maka Allah menciptakan manusia itu menurut gambar-Nya, menurut gambar Allah diciptakan-Nya dia ('adam); laki-laki (zakar) dan perempuan (neqevah) diciptakan-Nya mereka." Dalam ayat ini 'adam yang mulanya adalah tunggal tunggal kini didefinisikan kembali dengan bentuk jamak (mereka), hal ini untuk memperjelas bahwa di dalam 'adam (manusia) ada dua pribadi yaitu laki-laki dan perempuan kedua-duanya disebut sebagai 'adam (manusia). Dapat dimengerti bahwa bentuk keserupaan manusia dengan Allah adalah ketika manusia itu dipersatukan antara laki-laki dan perempuan menjadi satu pasangan, menjadi esa, menjadi lengkap (menjadi utuh) itulah yang disebut serupa dengan Allah.

Dalam ayat 27 dijelaskan bahwa 'dan di dalam citra Allah Ia menciptakannya, lakilaki dan perempuan, Ia menciptakan mereka.' Dalam kalimat ini terkandung dua kalimat yang setingkat, yaitu: (a) Kalimat pertama, "dan di dalam citra Allah, Ia (Allah) menciptakannya." (b) Kalimat kedua, "laki-laki dan perempuan, Ia menciptakan mereka." Dua kalimat setingkat ini sangat kontradiktif, karena kalimat pertama menjelaskan bahwa manusia yang diciptakan berbentuk tunggal (diwakili dengan kata 'menciptakan-'nya'), sedangkan kalimat kedua berbentuk jamak (diwakili dengan kalimat 'menciptakan mereka'). Pertanyaannya, sebenarnya manusia itu berbentuk jamak atau tunggal?

Kontras ini dapat dimengerti melalui kata penghubungan antara keduanya, yaitu: laki-laki (zakar: jenis kelamin jantan) dan perempuan (neqevah: jenis kelamin betina). Kalimat pertama menjelaskan bahwa manusia yang adalah gambar Allah bersifat tunggal, tetapi terdiri dua jenis kelami yaitu jantan dan betina (laki-laki dan perempuan). Sedangkan kalimat kedua menjelaskan bahwa manusia yang adalah gambar Allah, yang terdiri dari dua jenis kelamin, bersifat jamak. Tunggal dan jamak merupakan hakikat manusia, dalam pengertian bahwa manusia yang tunggal itu memiliki kejamakan dalam jenis kelami, yaitu jantan dan betina atau laki-laki dan perempuan. Dengan demikian yang disebut dengan manusia adalah seorang laki-laki yang berjenis kelamin jantan dan seorang perempuan yang berjenis kelamin betina. Laki-laki adalah keseluruhannya 
manusia demikian juga perempuan adalah keseluruhannya manusia. Laki-laki dan perempuan (jamak) adalah manusia (tunggal) yang setara dan mereka adalah gambar Allah yang diciptakan bersama dan pada waktu yang sama (Singgih, 2011).

Laki-laki dan perempuan ada dalam kesatuan kemanusiaan, dan dengan adanya dua jenis kelamin ini menunjukkan kesempurnaan manusia sebagai gambar Allah, karena hubungan kedua jenis kelamin manusia menggambarkan tentang persekutuan antara Allah dengan manusia. Kesegambaran manusia dengan Allah terdiri dari persekutuan Allah dengan manusia. Inilah yang disebut dengan ketunggalan manusia dalam bentuk keberadaannya yang jamak (Westermann, 1984). Penegasan ini meruntuhkan sebuah anggapan atau teori yang mengatakan bahwa penciptaan manusia dalam bentuk tunggal dan jamak itu memerlihatkan bahwa awalnya manusia itu satu dan kemudian dibelah menjadi laki-laki dan perempuan; dengan kata lain Allah menciptakan Adam sebagai androginus, yaitu makhluk yang memiliki koderat maskulin dan feminin secara bersamaan. Hal ini dipertegas denan tradisi penafsiran Yahudi yang mengatakan bahwa manusia diciptakan dalam satu bentuk tubuh tetapi memiliki dua wajah, sehingga manusia adalah makhluk hermaphrodite (Purnomo, 2019).

Dalam narasi kejadian pasal satu ini tentang penciptaan, manusia baik laki-laki maupun perempuan dijadikan bersama-sama, tidak ada yang mendahului satu dengan yang lain. Bahkan dalam ayat 28 Allah memberikan kepada manusia (laki-laki dan perempuan) kekuasaan atas ikan-ikan di laut dan burung-burung di udara dan atas segalah binatang yang merayap di bumi. Kekuasaan yang diberikan Allah bukan hanya berlaku untuk laki-laki tetapi juga perempuan karena mereka adalah manusia yang diciptakan Allah menurut gambar-Nya.

Kultus dari kisah penciptaan manusia dalam Kejadian pasal satu bukanlah manusia sebagai yang diciptakan, melaikan Sang Pencipta itu sendiri. Di mana di dalam Allah terdapat juga sifat laki-laki dan perempuan "baiklah kita (Elohim) menjadikan manusia (Adam) menurut gambar dan rupa kita". Seperti manusia yang dijadikan menurut gambar Allah yaitu laki-laki dan perempuan, begitu jugalah Allah yang memiliki sifat feminin dan maskulin. Hal ini didukung karena sumber P-lah yang menulis kisah penciptan di Kejadian pasal 1 dan kisah pengutusan Musa di Keluaran pasal 6. Para bapa leluhur Israel menggunakan nama El atau Elohim (dalam bentuk jamak) sebagai suatu bentuk penghormatan ketika mereka berbicara tentang Allah yang keduanya ditujukan kepada Allah El-Shadday (Hinson, 2012).

\section{El-Shadday dan Dewi Karema}

Mitologi penciptaan di suku Minahasa sebenarnya berusaha memaparkan bahwa betapa penuh kasih sayangnya seorang Dewi Karema terhadap umat manusia, sehingga dia datang ke dunia ini seperti yang dikisahkan dalam kisah penciptaan suku bantik Minahasa dan suku Toubulu Minahasa di atas. Betapa Dewi Karema ingin melahirkan suatu kehidupan dan membuatnya sebagai suatu keindahan yang dapat dinikmati oleh penduduk kalrutuang (sorga). Di sisi lain kisah penciptaan di suku Minahasa juga ingin menunjukan selayaknya dan merupakan keharusan bahwa perempuan itu di junjung dan 
dihormati sebagai pemberi hidup dan representasi dari Dewi karema, juga karena manusia pertama yang diciptaakan adalah perempuan yang bernama Lumimuut.

Peran dari Dewi Karema memiliki korelasi yang erat dengan El-Shadday sebagai gambaran keibuan yang sama, peran Dewi Karema dapat dimengerti sebagai kehadiran Allah El-Shadday dalam pemahaman ketuhanan di suku Minahasa. El-Shadday (Allah berpayudara) digambarkan sebagai Dewi Karema sang pemberi kehidupan bagi semua orang Minahasa. Sama seperti yang dikatkan oleh Clifford, bahwa menyebut Allah sebagai 'ibu' memberi sudut pandang tentang kehadiran Ilahi dalam bingkai gambaran yang akrab bagi manusia. Garis kesetaraan Allah dan 'ibu' membantu manusia mengetahui apa yang tidak dapat manusia bicarakan tanpa kata 'ibu'. Allah ibu adalah pemberi kehidupan dan selalu menghendaki segala sesuatu agar bertumbuh dan berkembang (Clifford, 2002).

\section{Implikasi}

Kehidupan budaya bukanlah kehidupan yang terpisah dengan keberagamaan, karena pada hakikatnya agama merupakan bagian integral dari kebudayaan. Tidak ada pemisahan antara agama dan budaya, keduanya harus menjadi satu kesatuan yang utuh dan saling memengaruhi satu sama lain (Panjaitan, 2020). Allah yang dikenal dalam Kekristenan adalah Allah yang juga hidup dalam budaya masyarakat Indonesia, termasuk dalam budaya suku Minahasa. Allah tidak pernah hidup terpisah dari manusia yang berbudaya, bahkan Allah yang menghidupi manusia dan budaya itu sendiri. Penelitian di atas membuktikan hal tersebut, di mana Allah dalam Perjanjian Lama yang dikenal dengan nama El Shadday dapat hidup dalam budaya suku Minahasa yang dikenal dengan nama Dewi Karema. Meskipun memiliki nama yang berbeda, namun keduanya adalah satu sosok yang sama, yaitu sosok seorang 'ibu' yang sangat peduli dengan kehidupan manusia yang adalah anak-anak-Nya. Dari kenyataan ini dapat ditegaskan bahwa suku Minahasa tidak perlu meninggalkan pemahaman dan penyebutan Dewi Karema serta menggantinya dengan nama Allah (El Shadday), karena ketika suku Minahasa menyebut nama Dewi Karema sebenarnya sudah menyebut nama Allah yang hidup secara nyata dalam kehidupan suku Minahasa.

\section{Rekomendasi untuk Penelitian Lanjutan}

Penelitian ini diharapkan dapat mendorong penelitian-penelitian lanjutan, khususnya mengenai upaya berteologi kontekstual di Indonesia. Karena penulis seringkali merasa prihatin terhadap kondisi berteologi di Indonesia yang seringkali mengabaikan keberadaan agama suku, bahkan memusuhi budaya yang dipandang sebagai bagian dari 'si jahat' (Panjaitan \& Siburian, 2019). Teologi kontekstual di Indonesia perlu dikembangkan, guna menemukan pemahaman yang komprehensif tentang Allah yang hidup, bukan hanya hidup dalam agama saja melainkan juga hidup serta menghidupi budaya yang ada di Indonesia. 


\section{Kesimpulan}

Dalam mitologi penciptaan manusia di suku Minahasa dapat ditemukan wajah Allah feminis yang diwakili oleh Dewi Karema yang melukiskan awal mula kejadian dunia dengan penuh cintah kasih melahirkan kehidupan di dunia ini. Dan hal ini tidak jauh berbeda dengan pesan yang tersurat di dalam Alkitab dan tradisi gereja tentang perjumpan Allah dengan budaya timur tengah kuno yang menjadi tradisi iman turuntemurun sampain saat ini. Kepercayaan terhadap mitologi kisah penciptaan membuat masyarakat Minahasa mengerti betul mengenai identitasnya sebagai anak-anak yang dilahirkan dari seorang ibu yang perlu untuk dijunjung dan dihormati. Sehingga dalam taraf sosial di tanah Minahasa, tidak ditemukan pembagian pekerjaan terhadap laki-laki dan perempuan, semua dianggap memiliki tanggungjawab dan kewajiban yang sama sebagai manusia. Pemaparan tentang mitologi penciptaan dari perspektif perempuan Minahasa bukan bermaksud untuk memaparkaan mitologi ini sebagai hal yang paling benar, masih ada juga mitologi yang sampai saat ini diyakini oleh masyarakat adat di Minahasa sebagai kebenaran.

Penulis memunculkan kembali kisah mitologi tentang Dewi Karema dan kisah penciptaan yang hampir mulai tenggelam oleh karena pandangan agama, budaya dan paham pendominasian sosial. Dalam uraian penelitian, ditemukan pemahaman bahwa tokoh yang tersohor dalam mitologi penciptaan manusia di suku Minahasa sebenarnya merupakan sosok yang hidup dari El-Shadday, yang dikenal dalam Perjanjian Lama. Dalam hal ini dapat dikatakan bahwa Allah yang dikenal dalam Perjanjian Lama tidak berhenti berfirman dan berkarya hanya pada konteks dan budaya orang Yahudi di Timur Tengah Kuno, dan tidak hanya sebatas yang dapat dipelajari dalam Alkitab. Allah yang berfirman dan berkaya juga dalam setiap komunitas masyarakat, masuk dalam setiap kebudayaan dan selalu hadir dalam sejarah peradaban dunia. Oleh karena itu, setiap suku bangsa memiliki perspektif yang berbeda-beda tentang konsep kealahan dan semuanya itu merupakan kebenaran interpretasi.

\section{Rujukan}

Clanton, J. A. (1990). In Whose Image? God and Gender. SCM Press.

EKA DIAH KARTININGRUM, Mk. (2015). PANDUAN PENYUSUNAN STUDI LITERATUR.

LEMBAGA PENELITIAN DAN PENGABDIAN MASYARAKAT POLITEKNIK KESEHATAN MAJAPAHIT MOJOKERTO.

Etikawati, A. I., Siregar, J. R., Jatnika, R., \& Widjaja, H. (2019). Pengembangan Instrumen

Pengasuhan Berbasis Nilai Budaya Jawa. Jurnal Ilmu Keluarga Dan Konsumen,

12(3). https://doi.org/10.24156/jikk.2019.12.3.208

Hinson, D. F. (2012). Buku Sejarah Israel Pada Zaman Alkitab. Bpk. Gunung Mulia.

J.Alb.T.Schwarz. (1907). Tontemboansche Teksten.

Kapahang-Kaunang, K. A. (1993). Perempuan: Pemahaman Teologis Tentang Perempuan

Dalam Konteks Budaya Minahasa. BPK Gunung Mulia.

Kol, H. V. (1903). Uit Onze Kolonien.

Lempp, W. (1987). Kejadian 1:1 - 4:26. BPK Gunung Mulia. 
Lubis, B. (Ed.). (2011). MITOLOGI NUSANTARA: PENERAPAN TEORI. Penerbit Quiksi. Lumingkewas, M. S. (2017). AGAMA MONARKI ISRAEL. Diandra.

LUMINGKEWAS, M. S. (2017). EL DAN WAHWEH. Diandra.

M.Clifford, A. (2002). Memperkenalkan Teologi Feminis. Ledalero.

Maller, A. S. (n.d.). El Shaddai: God's pre-marital name. THE TIME OF ISRAEL.

Nata, D. A. N. (Ed.). (2012). Ketika Perempuan Berteologi: Berteologi Feminis Kontekstual. TAMAN PUSTAKA KRISTEN.

Panjaitan, F. (2020). Membangun Teologi Pertanian Melalui Pembacaan Lintas Tekstual Injil Matius Dan Kosmologi Jawa. BONAFIDE: Jurnal Teologi Dan Pendidikan Kristen, 1(1), 44-64. https://doi.org/10.46558/bonafide.v1i1.8

Panjaitan, F. (2021). Membangun Nisbah Kehidupan Rumah Tangga: Tafsir Kolose 3:184:1. GEMA TEOLOGIKA: Jurnal Teologi Kontekstual Dan Filsafat Keilahian, 6(1), 81-94. https://doi.org/10.21460/gema.2021.61.659

Panjaitan, F., \& Siburian, H. H. (2019). Misi Kristologi dalam Konteks Kebudayaan. Logia: Jurnal Teologi Pentakosta, 1(1), 42-59. https://doi.org/https://doi.org/10.37731/log.v1i1.19

Purnomo, A. (2019). Dari Hawa Sampai Miryam: Menafsirkan Kisah Perempuan dalam Alkitab.

Rad, G. von. (1979). Genesis. SCM Press.

Rosenberg, D., \& Bloom, H. (1990). The Book of J. Faber \& Faber, Grove Weidenfeld.

Setiawan, D. E. (2020a). Menjembatani Injil dan Budaya dalam Misi Melalui Metode Kontektualisasi. Fidei: Jurnal Teologi Sistematika Dan Praktika, 3(2). https://doi.org/10.34081/fidei.v3i2.132

Setiawan, D. E. (2020b). Menjembatani Injil dan Kebudayaan dalam Misi Melalui Metode Kontekstualisasi. FIDEI: Jurnal Teologi Sistematika Dan Praktika, 3(2), 160-180. https://doi.org/https://doi.org/10.34081/fidei.v3i2.132

Setiawan, D. E. (2021). Ritus Pencurahan Darah Korban Binatang : Perjumpaan Injil Dengan Tradisi Manengeh Di Suku Dayak Bumate. Carka, Jurnal Teologi Bliblika Dan Praktika, 2, 1.

Singgih, E. G. (2011). Dari Eden ke Babel: Sebuah Tafsir Kejadian 1-11. PPST UKDW.

Stanislaus, S. (2019). Mengelola dan Memelihara Taman Eden: Inspirasi Biblis Peduli Ekologi. Kanisius.

Szuster, R. D. (2014). Teología feminista judía: diversas maneras de nombrar a la divinidad en la liturgia judía. Revista Espiga, 13(27). https://doi.org/10.22458/re.v13i27.500

Takaendengan, A. M. (2018). Analisis Sosio-Historis Terhadap Narasi Kebangsaan Tradisi Yahwisme Menurut Teori Nasionalisme Modern. Hibualamo Seri IlmuIlmu Sosial Dan Kependidikan.

Taulu, H. M. (1977). Mangorai.

Tiwery, W. Y. (n.d.). MANUSIA PERTAMA ITU NAMANYA INA: Membaca Narasi Mitos Penciptaan dari Perspektif Perempuan Maluku. Indonesian Jurnal of Theology, vol 5 no 2. 
Trible, P. (1992). God and the Rhetoric of Sexuality. SCM Press.

van Wolde, E. (1997). Stories of the Beginning: Genesis 1-11 and Other Creation Stories. Morehouse Publishing.

Vriezen, T. C. (2000). AGAMA ISRAEL KUNO. BPK Gunung Mulia.

Wenas, J. (2007). SEJARAH DAN KEBUDAYAAN MINAHASA. Institut Senibudaya Sulawesi Utara.

Westermann, C. (1984). Genesis 1-11: A Commentary. London and Ausburg Publishing House. 